\title{
The overload at work and outside of work: the case of woman operators of blistering
}

\author{
Raoni Rocha Simões ${ }^{\mathrm{a},{ }^{*}}$ and Vitor Guilherme Carneiro Figueiredo ${ }^{\mathrm{b}}$ \\ ${ }^{a}$ École Doctorale de Sciences Sociales, Laboratoire d'Ergonomie, Université Bordeaux 2, 146 rue Léo Saignat, \\ Bordeaux, France. \\ ${ }^{\mathrm{b}}$ Federal University of Itajubá (UNIFEI) - Campus Itabira, MG, Brasil.
}

\begin{abstract}
The internationalization of labor is a prominent feature of the economy today, but is accompanied by adverse effects on operator health. In general, musculoskeletal diseases are the first to appear in this context. The open observations activity and interviews with operators and the hierarchy have been made to discover the organizational constraints. Other interviews were also conducted to account for the determinants of activity outside of work. The use of video has allowed the registration of work cycles, which helped to describe and quantify the postures and gestures to establish a possible link between musculoskeletal diseases and work activity. The collected data were processed using software Actogram Kronos. To understand the process of origin of these diseases, the analysis of the socioeconomic context is also essential because they in part determine the organization of certain companies. The objective of this paper was to discuss the activities of operators of blistering in both work and outside work. The goal is to determine the constraints presents in these two spheres of activity, that may increase the risk of developing musculoskeletal diseases and to define their interaction.
\end{abstract}

Keywords: ergonomics work analysis, physical workload, repetitive strain injury, musculoskeletal disease, psychosocial factors.

\section{Introduction}

The internalization of work is a strong characteristic in modern economy and brings many effects in the health or workers. Among these effects the musculoskeletal diseases are in general the first manifestation of work overcharge [5].

The musculoskeletal diseases result of synergistic constrains (external) on the muscular tissues, area of reactions that exceed the individual functional capacity [10]. The need of the same motion structures compulsive repetition of actions - associated with (periarticulation) tendon structures compression, can reinforce the hypothesis that the overcharge of the organism, resulting of overcharge of activity is responsible for one more factor of the arise of musculoskeletal disease [9].
The psycho-social aspects such as highly stressful work, stress outside of work, extreme workday also act as musculoskeletal diseases [7]. The psychosocial environment of the work encompasses work organization and social work relations. Psychosocial factors are the ones related to interaction inside work environment, work content, organizational conditions, worker skills, needs, culture, personal extra work reasons, that can by means of perception and expertise, influence health, work performance and satisfaction in the work [6].

Current theories about the relationship between the psychosocial demands and musculoskeletal diseases associate directly to the stress generated by this demands to the increase of muscular activity. These theories confirm that there is influence of this stress over the perception of musculoskeletal diseases or in situations of stressful work conditions there is a reduced ability of the workers to cope with symptoms

\footnotetext{
*Corresponding author. E-mail: raoni.france@gmail.com
} 
increasing their perception. In case of muscular activity increased a via neuroendocrine, with elevation of epinephrine, norepinephrine and cortisol has been indicated as a response for psychosocial demands [8].

To understand the process of origin of these diseases its necessary to analyze the biomechanics of the gesture, work organization and the maneuvers adopted by the operator [10], as well as the analysis of the socio economical context [2]. Inside the limitations demanded by the organization of work and for the high productivity of the company is necessary a margin of maneuvers that workers establish strategies to enable production and or reduce the musculoskeletal demands over their bodies.

The purpose of this research is to discuss the activities of blister operators inside and outside work, seeking to determine the present constrains in these spheres of activities, how can one interact with another and the way they can increase the arising of musculoskeletal disorders.

\section{Methodology}

\section{$2.1-$ Context}

The company presented in this research is responsible for the fabrication of these medicines, liquid solid or doughy. The surveyed sector is named "Blistering", responsible for fabrication of chart tablets (denominated as Blister). This sector works 24 uninterrupted hours, being composed of 4 shifts that work in a 12 hour work journey for 36 hours rest. So each shift has 4 employees named "blister operators" summing 16 operators in the sector. Each shift with 4 operators responsible for the production in 2 blisters machines with a group coordinator who is responsible for surveying the sector.

The task prescribed to these employees by the company is: to produce the "blister" in a correct way, in other words with a tightly closed package without empty niches, feed the machine with raw material, feed the machines with bobbin, record the results of the production in each notebook used for this purpose, transport the medicine boxes inside the room, do the cleaning of the room. Pictures 1 and 2 show the operators performing the main activity in the sector or the production of blister.

\section{2 - Methods}

The methodology developed in this work combined qualitative techniques and quantitative data collection and analysis. Were made wide activities observations, interview with operators and coordinators, application of a heath questionnaire, medical records analysis, pictures and video records, and application of Kronos Software to analysis of the gestures developed in the realization of the activity.

Initially were made observations and interviews with operators and direct leadership. Open observations complemented with interview techniques are interesting tools to understand the first organizational constrains in the company [4]. So the 16 operators and the 4 production coordinators went through interview with around 30 minutes each. The interviews were led seeking also to understand the activities performed for the operators outside work.
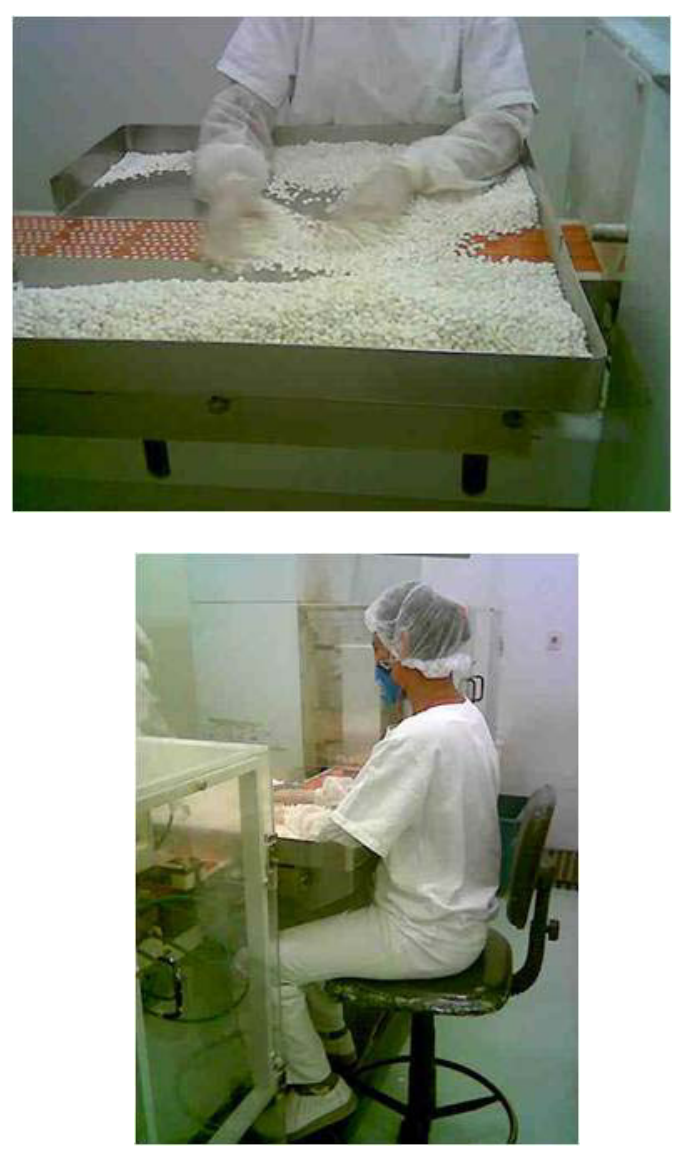

Fig. 1 and 2 - Blisters operator performing the activity of blister production. 
The application of a health questionnaire was performed with the purpose of understanding the main manifestations and symptoms noticed by the employees as well as their life habit. So the 16 operators answered the questionnaire. Self identification was optional allowing them to feel freer when answering the questions. To complement the questionnaire data was made an analysis of medical files between January and December 2009 trying to verify if was a correlation between the related symptoms and the diagnostics issued by the work doctor.

Were made records of the activities by pictures and videos, with the purpose of deepening over the knowledge about activities developed in the sector. The following analysis of this material allowed us to understand some constrains experienced in a work situation, record conflicting situations and confront some situations with operators opinions.

The record of activities and the movements from video images allowed us to determine the cycle of activities performed, allowing then to describe and quantify the gestures and posture adopted. This helped us to understand a possible connection between work and musculoskeletal diseases developed. The collected data were processed using the Actogram Kronos Software [1]. The data were collected in distinct days and moments, without any kind of criteria in the selection of the images. Then were gathered 14 extracts of the activities of Blistering by videos that range from 5 to 20 minutes footage.

\section{Results}

The results of the methods applied lead to matters related to organizational aspects, psycho social and orthopedic of employees of the sector. We will talk about each of this aspects bellow.

When it comes to organizational matters, diverse factors must be considered. The journey of 12 hours worked for 36 hours rest, is the same of work in alternated days. However the high productive demand of the company, the lack of enough employees in the sector and the financial needs of the operator, force that most of them work overtime constantly working day after day in the production. Moreover the main difficulties expressed revolve around matters connected to intense work rhythm and small margin of maneuvers of employees. The operators don't have autonomy to stop the machine and go to the bathroom when is needed. In this situation is necessary to call the production coordinator that evaluates the situation, and he has to decide to stop the machine or replace the operator for some minutes. This situation results of work overcharge on employees of the sector.

The psycho social aspects outside work also were approached with questionnaires and interviews. The questionnaires showed the $71 \%$ of the operators declared lack of time to do their domestic activities. Moreover only $18 \%$ declared to have time for leisure. Another factor showed is about sleeping hours. Around $55 \%$ of the operators declared to have only 6 hours sleep per night or less and that this period is not enough to rest. Around $44 \%$ declared to sleep in the bus or in the course house-work and vice-versa. The insufficient hours of sleep may be an important factor in the sense of discomfort and increase the feeling of body pain.

Another point extra work related by the employees concerns about the religious practice of the employees. Around $75 \%$ of the employees declared to have daily religious practice that is connected to Catholic culture dominant in the country and strongly present in the city and over the surroundings of the company. The feelings of mitigation and relieve of life problems and stress are constantly evoked by employees with phrases like "God watches over us" and "only Jesus saves".

The four employees in each group have no halts in their work journey and to perform their activities was stated a shift every one hour. While 2 are on the machines the other 2 remain standing organizing the boxes, positioning the medicines of the machine, making the record of production and cleaning the sector. While the employees are on the BLISTER, their activities are composed basically in a basic cycle, comprising 2 distinct moments.

1) The adjustment of charts in the treadmill which are held primarily movements of wrist and hand;

2) The distribution of the pill in the chart where are performed movements of rotation of the shoulder (adduction, abduction and flexion, extension ) with the purpose of "properly" loading all the pills in the pack niches.

There are still moments that the arms are kept leaned on the armrest of the chair. Generally this happens when the machine stops for some reason. The following graphics extracted from Software Kronos show the sequence of these movements in 3 distinct moments (in the adjustment of the chart, the movement of the shoulders and when the arms are kept leaned), the first during 9 minutes of observation and the second during 1 minute of observation (Figure 3). 
From the results of the graphic was possible to confirm that the movements of rotation of the shoulder are responsible for most part of the basic cycle of the activities performed by the worker. Movements of adjustment of the chart on the treadmill remain in 2nd place in the cycle, and for last the moment that the arms are kept leaned. Its possible to observe another graphic showing the analysis of movements in a smaller period (1 minute). This way the bars are more visible, what facilitates the general visualization of the graphic and the comparison amongst the 3 variables (Figure 4).

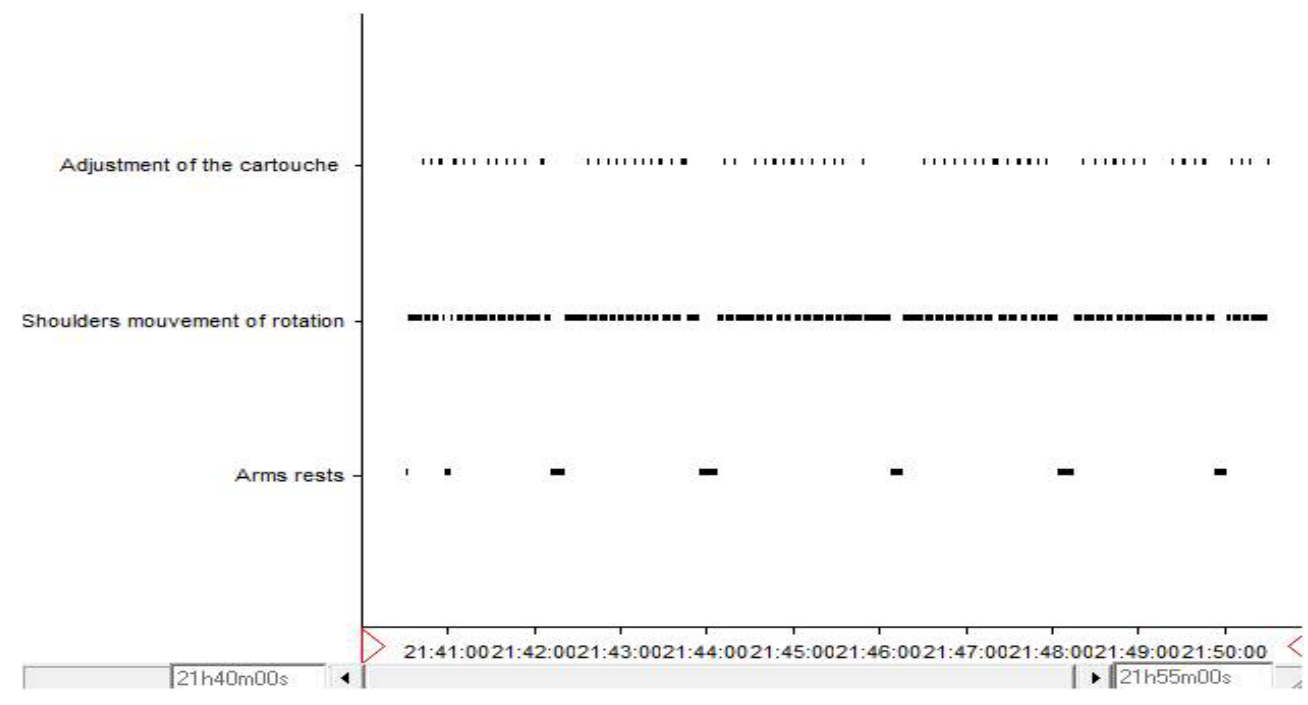

Fig. 3 - The analysis of the movements of Blistering during 9 minutes observations.

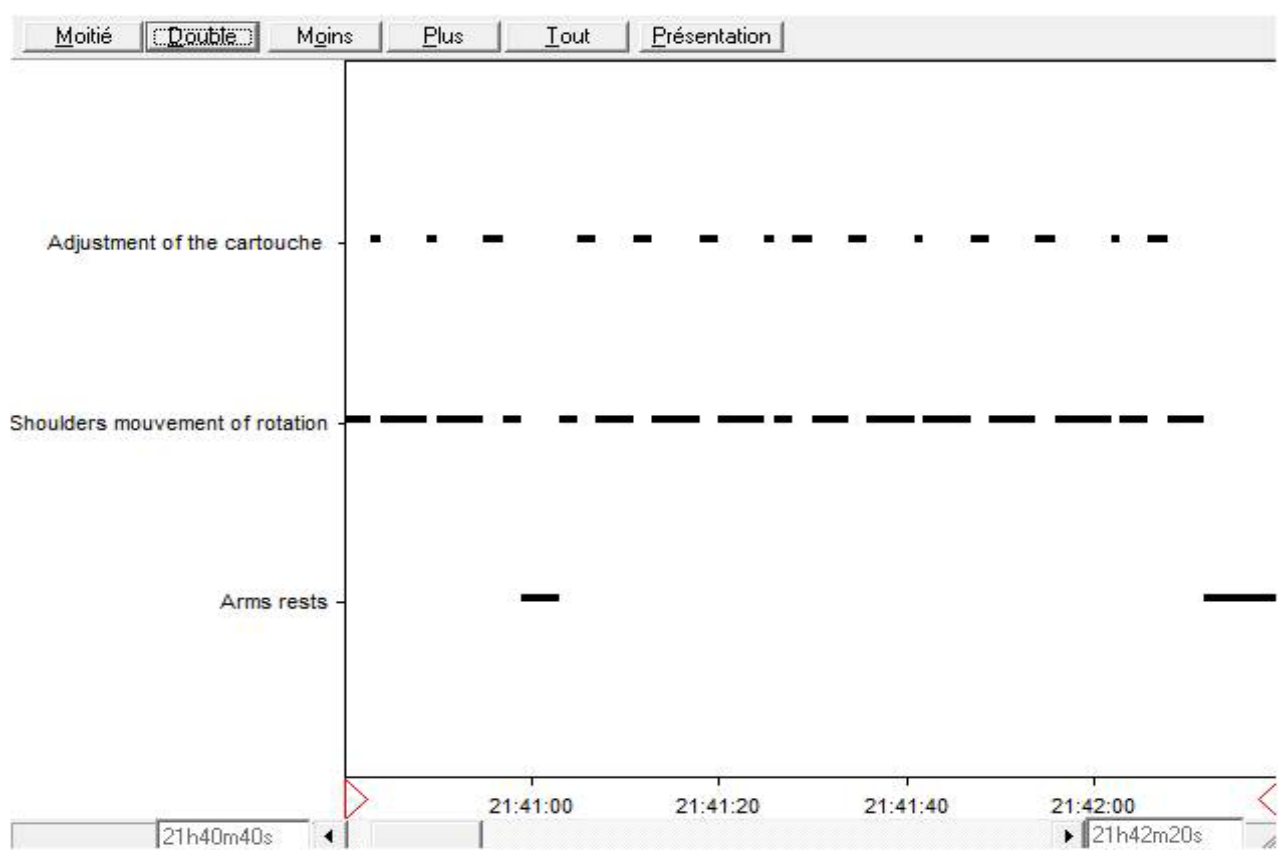

Fig. 4 - Analysis of movements of Blistering during 1 minute observation. 
Another data could be extracted from Kronos Software. From it is noticeable that the movements of the upper members in the Blistering are constants, of long duration and the shoulder movements are responsible for the biggest part of it (around 70\%) of the basic cycle of the activity (Figure 5).
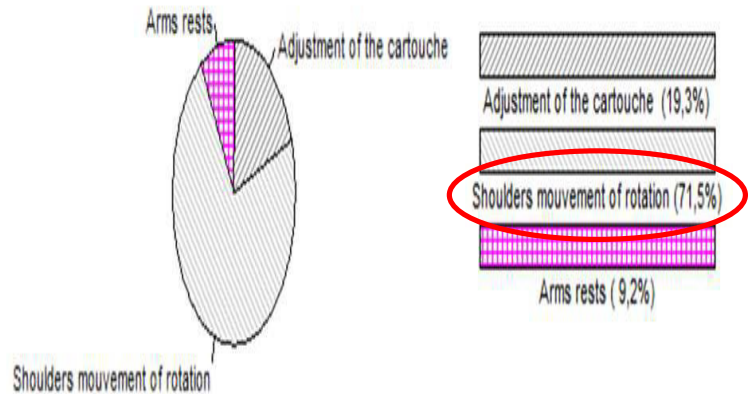

\section{Shouders movementio it rotition}

Fig. 5 - Percentage of the moments observed in the cycle of activities.

Considering that the journey of the employees has 12 hours, that the shift is made each 1 hour, that the movements of rotation of the shoulders are responsible for more than $70 \%$ percent of the cycle of activities, is possible to assure that the operators of Blister remain around 4 daily hours with the shoulders performing movements of rotation.

15 out of 16 employees presents in the sector manifested some kind of pain or discomfort musculoskeletal and 12 had already some orthopedic diagnostic from the work doctor between January and December 2009. Analyzing the medical diagnostics emitted 9 of it are from musculoskeletal diseases connected to the upper muscles and the other 3 were diagnosed in the cervical spine of lumbar. The pain and the discomfort manifested in the questionnaires and interviews follow this logic, with the 15 employees relating symptoms on the upper members or spine or in both regions.

\section{Discussion}

By the present research was verified that the individual characteristic related do sex, to the education level and the need of financial contribution lead many women of the region to work in this company that is one of the few big companies presents in this region.
The margin of the maneuvers seems to be restricted for the operator to create a time of recovering. Appear symptoms musculoskeletal of upper members that influence some aspects of daily life as lacking of perception to perform domestic activities and sensation of few hours of sleep.

It is necessary to consider that great part of the operator have daily religious practice. This context can influence the researched situation in the sense that part of the pain or problems during the workday is mitigated by religious devotion and by the employees verbalization that see in the practice a relieve for the problem accumulated in the work. This cultural aspect shows the difference of temporal representations between the ways of life and work organization.

The work organization don't allow the operator to make halts and their lives outside work and doesn't provide significant periods of rest. All this physical and organizational constrains influenced the operators health and their way of life [3].

\section{References}

[1] A. Kerguelen, Pre-and post-observational categorisation of observables: application to the Kronos software aid for activity analysis, in: Y. Quéinnec, F. Daniellou F., eds., Designing for everyone, Paris: Taylor \& Francis, 1991.

[2] A. Nouroudine, Techniques et cultures: comment s'appropriet-on des technologies transférées? In: Octarès Éditions, Toulouse, 2001.

[3] A. Wisner, A Metodologia na Ergonomia: ontem e hoje. In: A inteligência no trabalho. Tradução de Roberto Leal Ferreira. São Paulo: UNESP/FUNDACENTRO, 1991.

[4] F. Guérin, A. Laville, F. Daniellou, J. Duraffourg and A. Kerguelen, Comprendre le travail pour le transformer: la pratique de l'ergonomie, in: ANACT, Lyon, 1997.

[5] G. Raouf, F. Catherine, K. Taoufik and S. Francis, Analyse des facteurs socioculturels et survenue des troubles musculosquelettiques: le cas des couturières en Tunisie, in Pistes, vol.12, no.2, 2010.

[6] International Labour Office, Psychosocial factors at work: recognition and control. Report of the Joint ILO/WHO Committee on Occupational Health - Ninth Session. Geneva apud M. C. Martinez and A. I. B. Paraguay, Satisfação e Saúde no Trabalho - aspectos conceituais e metodológicos, in: Cadernos de Psicologia Social do Trabalho, vol. 6, 2003.

[7] P. M. Bongers, A. M. Kremer and J. ter Laak, Are psychosocial factors, risk factors for symptoms and signs of the shoulder, elbow or hand/wrist? A review of the epidemiological literature, in: Am. J. Ind. Med., vol.41, no5, 2002.

[8] R. de Cássia Fernandes. Distúrbio músculo-esquelético industrial e trabalho industrial, Doutorado, Dissertação, Universidade da Bahia, 2004.

[9] Y. Clot, Action et connaissance en clinique de l'activité, in: (a) activitiés, vol.1, no.1, 2004.

[10] Y. Clot and G. Fernandez, Analyse psychologique du mouvement: apport à la compréhension des TMS, in : @activitiés, vol.2, no. 268,2005 